\title{
Review Article \\ Update in Pathogenesis and Prospective in Treatment of Necrotizing Enterocolitis
}

\author{
Gianluca Terrin, ${ }^{1}$ Antonella Scipione, ${ }^{2}$ and Mario De Curtis ${ }^{2}$ \\ ${ }^{1}$ Department of Perinatal Medicine, Sapienza University, Viale del Policlinico 155, 00161 Rome, Italy \\ ${ }^{2}$ Department of Pediatrics and Infant's Neuropsychiatry, University of Rome "La Sapienza", Rome, Italy \\ Correspondence should be addressed to Gianluca Terrin; gianluca.terrin@uniromal.it
}

Received 27 February 2014; Accepted 24 June 2014; Published 17 July 2014

Academic Editor: Mikihiro Fujiya

Copyright (c) 2014 Gianluca Terrin et al. This is an open access article distributed under the Creative Commons Attribution License, which permits unrestricted use, distribution, and reproduction in any medium, provided the original work is properly cited.

\begin{abstract}
Necrotizing enterocolitis (NEC) is among the most common and devastating diseases in neonates and, despite the significant advances in neonatal clinical and basic science investigations, its etiology is largely understood, specific treatment strategies are lacking, and morbidity and mortality remain high. Improvements in the understanding of pathogenesis of NEC may have therapeutic consequences. Pharmacologic inhibition of toll-like receptor signaling, the use of novel nutritional strategies, and microflora modulation may represent novel promising approaches to the prevention and treatment of NEC. This review, starting from the recent acquisitions in the pathogenic mechanisms of NEC, focuses on current and possible therapeutic perspectives.
\end{abstract}

\section{Introduction}

Necrotizing enterocolitis (NEC) is an inflammatory disease of the intestine, often associated with sepsis and frequently complicated by perforation, peritonitis, and death. Despite the significant advances in neonatal clinical and basic science investigation, NEC often is an incurable disease. Specific therapeutic strategies are lacking because unknown etiology. Mortality rate is high and long-term prognosis in survivals is very poor. The inflammatory process, starting from intestinal mucosa, involves distant organs including the central nervous system, with an increased risk for neurodevelopment delay $[1,2]$. The total annual estimated cost of caring for affected infants with NEC only in the United States ranges between $\$ 500$ million and $\$ 1$ billion [3]. For these reasons, NEC has become a priority for research.

The term "necrotizing enterocolitis" (NEC) often reflects a spectrum of intestinal conditions that differ with respect to the pathogenesis [1]. Classical form of NEC usually occurs in preterm neonates in the first 2 weeks of life. Spontaneous intestinal perforation, often diagnosed as NEC, occurs in a term neonates and it could be observed also several days after birth. This condition probably represents a different disease with a different pathogenesis, it is independent by modalities of feeding, and it is characterized by only minimal intestinal inflammation and/or necrosis $[3,4]$. Our review focuses on recent advances in pathogenesis and potential therapeutic options of classical form of NEC.

\section{Pathogenesis of Necrotizing Enterocolitis}

Despite the fact that the pathogenesis of NEC is considered multifactorial, recently the role of epithelium has emerged as central in the development of NEC. The loss of epithelial barrier allows pathogens translocation from the intestinal lumen to the mucosa (Figure 1). Innate immunity regulates epithelial barrier in experimental model and human cases of NEC.

2.1. Epithelial Barrier. The intestinal mucosa of the premature infant presents a persistent equilibrium state between injury and repair. Injury to the intestinal mucosa may depend on a variety of conditions typical of prematurity, including hypoxia [5, 6], infection [7], and starvation [8]. Microcirculatory dysfunction contributes to epithelial damage [9]. 


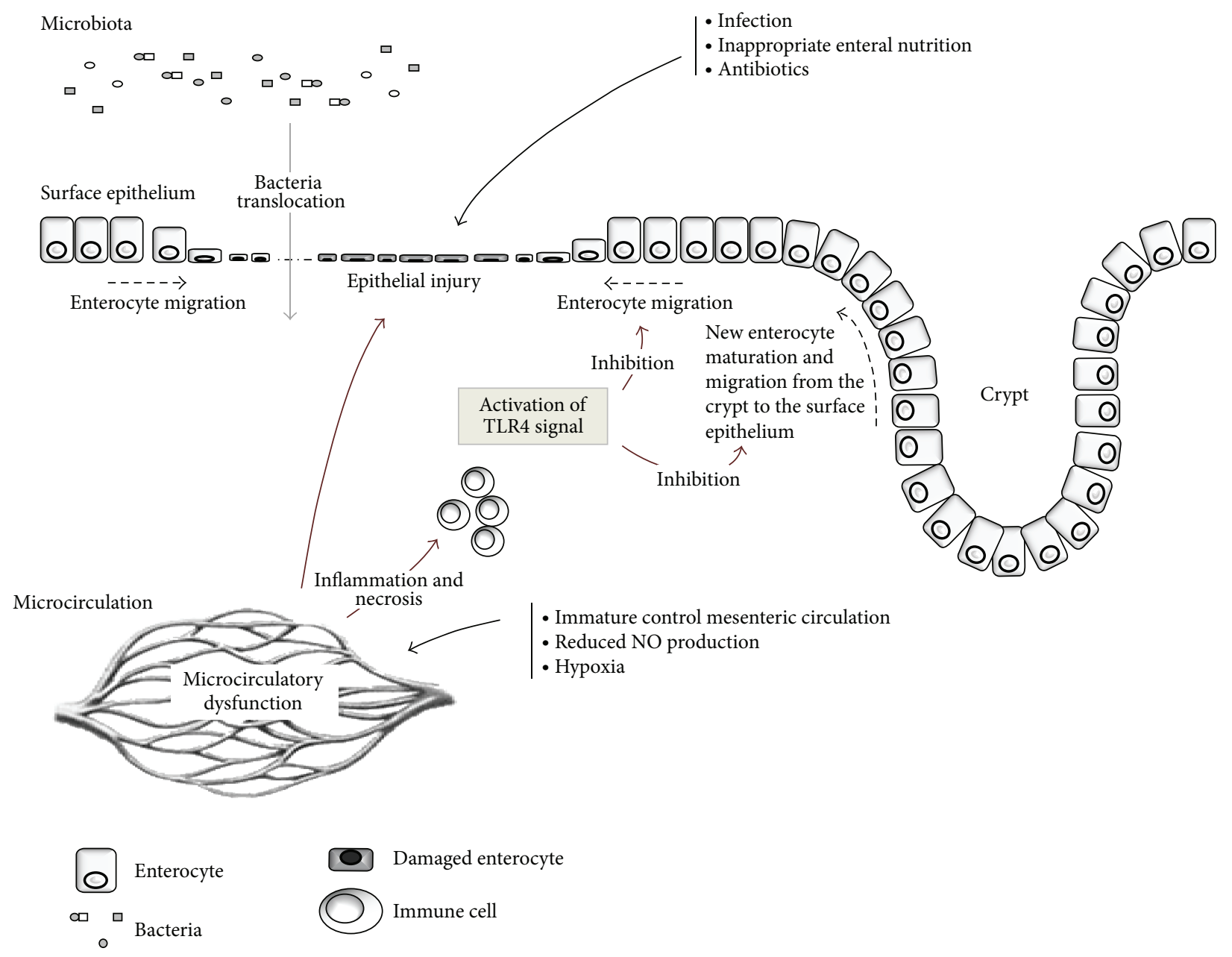

FIGURE 1: The role of TLR4 in epithelium injury and repair mechanisms. Many factors typical of prenatal birth such as infections, inappropriate enteral nutrition, antibiotics use, microcirculatory dysfunction, and hypoxia induce epithelial injury. Hyperactivation of TLR4 signaling affects the healing process favoring pathological bacteria translocation across epithelial barrier.

In physiological conditions, healing of epithelium begins immediately after the injury with mature enterocyte migration from health to the wounded area [10]. Subsequently, the proliferation of new enterocytes within the crypts of Lieberkuhn completes the process of repair [11]. It has been recently suggested that NEC is associated with a marked inhibition in both enterocyte migration and proliferation, making the host uniquely susceptible to further injury and finally to bacterial translocation [12].

2.2. Innate Immunity: The Role of Toll-Like Receptor. Innate immunity structured components located on the epithelial surface, which play a major role in tissue repair, are the tolllike receptors (TLRs). Among the known human TLRs, type 4 seems to have a crucial role in NEC development [12-14]. TLR4 may be activated by bacterial (i.e., lipopolysaccharides) or by other innate immunity components (i.e., high-mobility group box 1) [15]. The activation of TLR4 inhibits enterocyte migration and leads to enterocyte apoptosis in mice model, via nuclear factor kappa light chain enhancer of activated $\mathrm{B}$ cells $(\mathrm{NF} \kappa \mathrm{B})$ pathway activation, whereas the inhibition of TLR4 signaling in the intestinal epithelium prevents NEC development and attenuates the degree of enterocyte apoptosis in mice model and cell cultures [12-14]. Developing fetuses express elevated levels of TLR4 until the end of the gestation. This overexpression could be due to the role of TLR4 in regulating proliferation and differentiation of the intestinal epithelium during embryogenetic period [16]. The persistently elevated expression of TLR4 during intrauterine life does not increase the risk of NEC for the fetus, probably because it lives in a sterile or quasi-sterile environment. At the end of gestation, the neonate expresses low levels of TLR4 and, in the presence of a normal intestinal microflora, the signal remains inactivated. By contrast, the expression of TRL4 in preterm babies is very high, and when the premature intestine is colonized by pathologic microflora, TLR4 signal could be overactivated, leading to decreased ability to repair 
TABle 1: Pathogens associated with necrotizing enterocolitis in neonates.

\begin{tabular}{lcc}
\hline Bacteria species & Virus & Fungi \\
\hline Escherichia coli [25] & Rotavirus [26] & Candida albicans [27] \\
Pseudomonas aeruginosa [28] & Adenovirus [29] & Candida glabrata [27] \\
Klebsiella [30] & Norovirus [31] & \\
Cronobacter sakazakii [33] & Astrovirus [34] & \\
Shigella boydii [35] & Echovirus [36] \\
Coagulase-negative Staphylococcus [37] & Cytomegalovirus [7] \\
Clostridium spp. [38] & Coxsackie virus [39] \\
Campylobacter [40] & Torovirus [41] \\
Enterobacter cloacae [42] & Coronavirus [43] \\
Salmonella [44] & & \\
\hline
\end{tabular}

epithelium after injury. The final effect of this TLR4-mediated response is gut barrier failure, bacterial translocation, intestinal inflammation, and finally activation of systemic inflammatory response [12]. However, the observation that most premature infants do not develop NEC, despite the seemingly tonic activation of TLR4, suggests that TLR4 signal is somehow curtailed within the newborn intestinal epithelium, thus limiting the propensity to NEC development. It seems, therefore, that the consequences of exaggerated TLR4 signal in premature neonates can be confined by counterregulatory mechanisms that limit the consequences of TLR4 activation. These mechanisms include intra- and extracellular factors and probably may be influenced by microflora composition (Figure 2).

Heat shock proteins, of which Hsp70 is a predominant member, are a family of intracellular proteins activated by a variety of stressors, which contribute to the delivery of target proteins to the ubiquitin-proteosome system for degradation through cochaperone molecules, namely, carboxyl terminus of Hsp70-interacting protein (CHIP) [17]. Hsp70 has a protective role in the intestine limiting TLR4 signal in enterocytes. Hsp70 promotes CHIP-mediated ubiquitination and consequent degradation of TLR4 [18]. TLR4 activation itself significantly increased Hsp70 expression in enterocytes, which provides a mechanism of autoinhibition of TLR4 signal (Figure 2). Reduced activity of Hsp70 or hyperactivation of TLR disrupts this balance and induces NEC. On the contrary, upregulation of Hsp70 leads to a reduction in TLR4 signal (Figure 2) [18]. Interestingly, an extracellular factor possibly affecting TLR4 signal is the epidermal growth factor (EGF). The fetus continuously swallows amniotic fluid that limits the amplification of TLR4 signaling in the fetal intestinal mucosa and in cultured enterocytes exposed to bacterial products [19], thus markedly reducing the degree of proinflammatory cytokine release. Amniotic fluid is extremely rich in EGF. This extracellular factor inhibits TLR4 signaling via peroxisome proliferator-activated receptor gamma $(\operatorname{PPAR} \gamma)$ and $\mathrm{NF} \kappa \mathrm{B}$ pathway (Figure 2) [19]. Other important factors, at least in part related to TLR signaling, have been recently explored in the pathogenesis of NEC (Figure 2). TLR4 signaling cans upregulate platelet-activating factor (PAF) expression thus increasing risk of injury in experimental models of NEC $[20,21]$. Accumulation of ileal bile acids causes significant injury in the small intestine and acts in concert with TLR4 pathway [22]. Intestinal integrity restitution requires intercellular connectivity, mediated through small channels, namely, gap junctions, rich in connexin protein [23]. Proinflammatory cytokines (i.e., INF $\gamma$ ) cause the internalization of connexin 43 , thereby impairing intercellular connectivity and reducing the extent of intestinal restitution (Figure 2) [24].

2.3. Gut Microbiota. Nearly all the studies on NEC associate infections with the disease. However, no specific microbe has been identified as determinant etiologic factor, and, rather surprisingly, the specific mechanisms by which infections contribute to NEC remain unknown. On the other hand, many pathogens may simulate a picture of NEC in neonates (Table 1) [7, 25-44]. The use of new molecular biology techniques has provided opportunities to reexamine this unresolved problem. Recent studies have identified an abundance of Proteobacteria (including many commonly observed Gram-negative pathogens) in fecal samples of babies that will develop NEC [45-47]. Additional demonstrated findings included a loss of gut microbial diversity and depletion of enterococcal populations in the feces, before NEC development [47]. More recently, a correlation between the clinical finding of pneumatosis intestinalis and the presence of clostridial species (Clostridium butyricum and Clostridium paraputrificum) has been proposed [48]. All these data suggest that NEC may not result from a single causative species, but more likely from a currently undefined dysbiosis, that may favor TLR4 activation and pathogens translocation across the epithelium.

\section{Promising Therapeutic Options}

The mainstay in the prevention and treatment of NEC remains a correct management of fluid intake, nutrition, prevention of infections, and adequate antibiotic therapy [1-4]. On the basis of the most recent evidences in the understanding of the pathogenic mechanisms, new therapeutic 


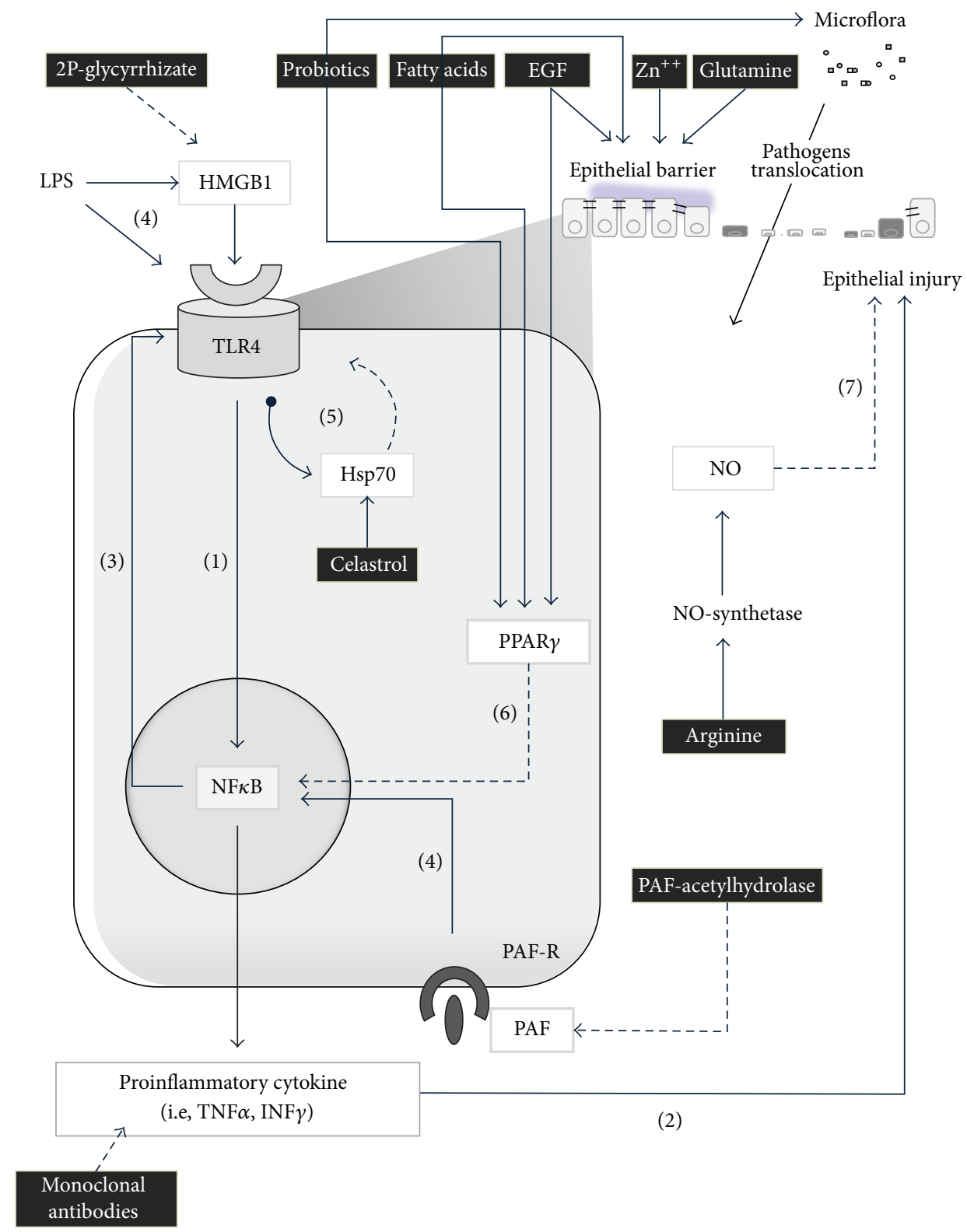

$\longrightarrow$ Induction

$-\rightarrow$ Inhibition

FIGURE 2: Possible therapeutic interventions on molecular mechanism inducing necrotizing enterocolitis. (1) TLR4 induces proinflammatory

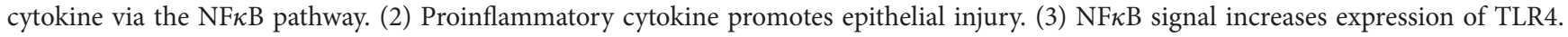
(4) TLR signal may be induced directly by bacterial products (i.e., LPS), HMGB1, and via NFאB by PAF activated receptor (PAF-R). (5) TRL4 is autoregulated by hsp70 proteins. (6) PPAR, blocking NF $\kappa$ B pathway, is a potent inhibitor of TRL4 signal. (7) Nitric oxide (NO), produced by NO-synthetase, protects epithelium from injury. Evidenced in black-block we have reported molecules that may have potential therapeutic role in necrotizing enterocolitis, interfering with TRL4 signaling (i.e., inhibition of HMGB1 by 2-P-glycyrrhizate; induction of PPAR by probiotics, fatty acids, and EGF; PAF hydrolysis by PAF-acetylhydrolase; induction of Hsp70 by Celastrol; blocking proinflammatory cytokine by monoclonal antibodies), or maintaining epithelial barrier integrity (i.e., fatty acids, EGF, zinc, and glutamine) or protecting against epithelial injury (i.e., NO, probiotics). Please note that this is a simplified cartoon; thus reported molecules may play many other functions at mucosal and systemic level that may interfere with the development of necrotizing enterocolitis (see the text). Direct effects of TLR4 on epithelium are reported in Figure 1. 
approaches can be hypothesized. Recent advances in the knowledge of pathogenic mechanism suggest that future treatment may involve immunological approaches, such as pharmacologic inhibition of TLR signal, manipulation of the intestinal environment other than administration of specific nutrients. Some options have been tested in clinical trials; many others should be developed and verified in clinical setting in the next studies (Figure 2).

\subsection{Preservation of Epithelial Barrier by Nutritional Inter-} ventions. The adoption of adequate feeding strategies and the use of specific molecules in enteral nutrition may have a positive impact on the risk of NEC. Human milk is able to promote maturation of gastrointestinal tract in preterm neonates [49-51]. The positive effects of human milk have been attributed to several factors (i.e., macrophages, lymphocytes, sIgA, lysozyme, lactoferrin, oligosaccharides, nucleotides, cytokines, growth factors, and enzymes), but a specific component to transfer in preterm formula has not been definitively identified [50].

Endothelial nitric oxide is an important regulator of vascular perfusion and is synthesized from the amino acid L-arginine. Hypoargininemia is frequently observed in preterm neonates and may predispose them to NEC. Recently, Polycarpou et al. have demonstrated that enteral L-arginine supplementation can be safely administered in VLBW neonates and appears to reduce the incidence of stage III NEC [52]. However, larger studies are needed to further evaluate the effect of L-arginine supplementation in preventing NEC in VLBW infants [53]. Enteral glutamine supplementation decreased gastrointestinal dysfunction, number of days when feeding was withheld, and serious infectious episodes [54]. Moreover, experimental studies have shown that glutamine plays an important role in maintaining the functional integrity of the gut by serving as fuel for enterocytes, stimulating mucosal cell proliferation and differentiation, improving mucus quality, and maintaining the integrity of tight junctions [54]. Improved intestinal integrity, in turn, decreases probability of bacterial translocation and of systemic spread of bacteria [55, 56]. However, so far only animal studies have provided direct evidence for this hypothesis.

A protective role of EGF has been demonstrated mainly in animal model of NEC $[57,58]$. EGF contained in amniotic fluid promotes epithelial repair by inhibition of TLR4 signal (Figure 2). EGF was tested only in one small trial including 8 cases of neonates [59]; further studies in human are advocated to verify the efficacy of EGF or amniotic fluid in preventing NEC. This study demonstrates that EGF is well tolerated and produced positive and measurable remodeling trophic effects on the gastrointestinal mucosa.

Short chain fatty acids (SCFA), derived from fermentation of undigested carbohydrates by intestinal microflora, have important effects on epithelial functions and maturation and a potent anti-inflammatory power on the mucosa [60, 61]. Despite potential therapeutic utility of SCFA in neonates at risk of NEC, no studies testing the efficacy of these molecules are available at the moment.
Zinc is ubiquitous element that participates in many metabolic pathways. The use of zinc to prevent NEC is supported by evidences demonstrating the role of zinc in maintenance of epithelial barrier function and induction of adequate immune response (Figure 2) in experimental model of NEC [62]. Recent clinical trial demonstrates the efficacy of oral zinc supplementation in reducing NEC in preterm neonates when administered at high doses [62].

3.2. Modulation of TLR4 Signal. The pharmacological upregulation of Hsp70 within the intestinal mucosa by Celastrol, a novel cell permeable triterpenoid antioxidant, has been tested in a mice model of NEC $[63,64]$. Celastrol reduces enterocyte apoptosis and attenuates severity of NEC, but studies in human are still lacking. At the same time, it is possible to hypothesize a modulation of TLR signaling throughout different ways, as indicated in Figure 2 [19, 24, 59]. Further studies are required to establish real applicability of these novel therapeutic options to prevent and treat human cases of NEC.

3.3. Modification of Gut Microbiota Composition. A relatively well-studied approach to manipulate gut microbiome is the administration of probiotics. Although its efficacy in the prevention and treatment of NEC has been demonstrated in some articles [65], more works are critically needed to determine well-tolerated and effective dosing strategies and to identify the long-term effects of microbial manipulation on health and development (Table 2). The extrapolation of available evidences for probiotics to preterm neonates should take into account the characteristics of the products utilized and of the population included in the examined studies. A specific strain used in a population from a developed country may not be effective in neonates from other countries, who may have different environmental and genetic conditions. Thus, debate as to whether to give probiotics systematically to preterm infants is still ongoing. The American Pediatric Surgical Association Outcomes and Clinical Trials Committee systematic review concluded in 2012 was in support of the recent Cochrane reviews regarding the use of prophylactic probiotics in preterm infants weighing less than $2500 \mathrm{~g}$ to reduce the incidence of NEC [66]. However, there are no high levels of evidences to recommend the routine use of probiotics in order to decrease NEC occurrence [67]. Many aspects may have influenced the different results obtained in different trials [67]. In particular, the baseline NEC rate was a major factor affecting the potential benefit of probiotic supplementation in a specific population. The effect of probiotics decreases dramatically in areas where the occurrence of NEC is low ( $<5 \%$ of very low birth weight infants); hence further studies are needed before a benefit in these areas can be established. The main limitation to future trials is the large sample sizes required to demonstrate the benefit of probiotics in this setting. Mihatsch et al. calculated that, with a $5 \%$ baseline incidence of NEC, at least 714 infants per group would be required to demonstrate a $50 \%$ reduction rate by probiotics $(\alpha=0.05, \beta=0.2)$ [67]. Despite the larger 
TABle 2: Potential benefits and demonstrated limits of probiotics.

\begin{tabular}{ll}
\hline Rational for the use of probiotics & Probiotics use in the clinical practice \\
\hline $\begin{array}{l}\text { Probiotics supplementation inhibits pathogenic } \\
\text { colonization and produces anti-inflammatory effects }\end{array}$ & $\begin{array}{l}\text { Neonatal Intensive Care Units with higher rates of } \\
\text { NEC are more likely to observe a benefit with } \\
\text { probiotic supplementation }\end{array}$ \\
$\begin{array}{l}\text { Probiotics secrete lactic acid to lower local pH, } \\
\text { which inhibits the growth of pathogenic bacteria }\end{array}$ & $\begin{array}{l}\text { Multistrain probiotics may be more effective than } \\
\text { single-strain products }\end{array}$ \\
$\begin{array}{l}\text { Probiotics communicate directly with pathogenic } \\
\text { bacteria modulating their gene expression in order } \\
\text { to reduce binding proteins to host epithelial cells }\end{array}$ & $\begin{array}{l}\text { Extremely low-birth-weight infants may not benefit } \\
\text { to the extent observed in those with greater }\end{array}$ \\
$\begin{array}{l}\text { Probiotics stimulate production of secretory } \\
\text { immunoglobulins and positively influence immunity } \\
\text { response }\end{array}$ & $\begin{array}{l}\text { Although reports of probiotic-related sepsis are } \\
\text { limited, caution should be used when considering } \\
\text { probiotic supplementation in infants at greatest risk } \\
\text { for an impaired mucosal barrier }\end{array}$ \\
& $\begin{array}{l}\text { Policies regarding storage, preparation, distribution, } \\
\text { administration, and documentation of probiotics to } \\
\text { ensure patient safety should be adopted }\end{array}$ \\
\hline
\end{tabular}

clinical trials currently underway, there are no ongoing trials targeting a sample size that large. In addition, many drugs currently used in neonatal intensive care unit may modify microbiota composition (i.e., antibiotics, probiotics) and, thus, may influence the efficacy of such intervention of microflora manipulation.

Gastric acidity inhibitors drugs, largely used in neonatology, modify intestinal microflora and increase the risk of NEC $[68,69]$. Limitation of their use should be considered as immediate efficacious strategy to reduce NEC incidence.

A novel perspective to manipulate intestinal microflora is represented by fecal transplantation. This technique has proven effective in the treatment of refractory colitis by Clostridium difficile and in some cases of inflammatory bowel disease [70-72]. Fecal transplantation involves direct transfer of fecal material from a healthy donor to a recipient's upper or lower intestinal tract [70-72]. No data are currently available for neonates with NEC, and important limitations should be considered before to hypothesize this therapeutic option in neonatology (i.e., modalities of transfer of fecal material from donor to recipient and/or the choice of donor).

\section{Conclusions}

A better understanding of the early mechanisms at the basis of NEC development will offer new and innovative therapeutic approaches to this severe condition. To improve the clinical management and limit the complications associated with NEC, future studies should start from the central role of the epithelium, innate immunity, and microbiota. It would be essential to explore the interaction between these main pathogenetic factors in order to hypothesize new efficacious therapeutic strategies. Further well-designed trials in selected populations are advocated to verify the efficacy of the new pharmacological and nutritional approaches hypothesized in this review.

\section{Conflict of Interests}

The authors declare that there is no conflict of interests regarding the publication of this paper.

\section{References}

[1] S. R. Hintz, D. E. Kendrick, B. J. Stoll et al., "Neurodevelopmental and growth outcomes of extremely low birth weight infants after necrotizing enterocolitis," Pediatrics, vol. 115, no. 3, pp. 696-703, 2005.

[2] A. D. Bedrick, "Necrotizing enterocolitis: neurodevelopmental "Risky Business'”' Journal of Perinatology, vol. 24, no. 9, pp. 531533, 2004.

[3] J. Neu and W. A. Walker, "Necrotizing enterocolitis," The New England Journal of Medicine, vol. 364, no. 3, pp. 255-264, 2011.

[4] S. C. Fitzgibbons, Y. Ching, D. Yu et al., "Mortality of necrotizing enterocolitis expressed by birth weight categories," Journal of Pediatric Surgery, vol. 44, no. 6, pp. 1072-1076, 2009.

[5] C. Zhang, M. P. Sherman, L. S. Prince et al., "Paneth cell ablation in the presence of Klebsiella pneumoniae induces necrotizing enterocolitis (NEC)-like injury in the small intestine of immature mice," Disease Models and Mechanisms, vol. 5, no. 4, pp. 522-532, 2012.

[6] R. Ozdemir, S. Yurttutan, F. N. Sari et al., "Antioxidant effects of $\mathrm{N}$-acetylcysteine in a neonatal rat model of necrotizing enterocolitis," Journal of Pediatric Surgery, vol. 47, no. 9, pp. 1652-1657, 2012.

[7] L. Tran, M. Ferris, J. Norori et al., "Necrotizing enterocolitis and cytomegalovirus infection in a premature infant," Pediatrics, vol. 131, no. 1, pp. e318-e322, 2013.

[8] C. D. Downard, E. Renaud, S. D. St. Peter et al., "Treatment of necrotizing enterocolitis: an American pediatric surgical association outcomes and clinical trials committee systematic review," Journal of Pediatric Surgery, vol. 47, no. 11, pp. 2111-2122, 2012. 
[9] H.-Y. Zhang, F. Wang, and J.-X. Feng, "Intestinal microcirculatory dysfunction and neonatal necrotizing enterocolitis," Chinese Medical Journal, vol. 126, no. 9, pp. 1771-1778, 2013.

[10] M. D. Neal, C. P. Sodhi, M. Dyer et al., "A critical role for TLR4 induction of autophagy in the regulation of enterocyte migration and the pathogenesis of necrotizing enterocolitis," Journal of Immunology, vol. 190, no. 7, pp. 3541-3551, 2013.

[11] J. M. Richter, B. L. Schanbacher, H. Huang, J. Xue, J. A. Bauer, and P. J. Giannone, "LPS-binding protein enables intestinal epithelial restitution despite LPS exposure," Journal of Pediatric Gastroenterology and Nutrition, vol. 54, no. 5, pp. 639-644, 2012.

[12] C. L. Leaphart, J. Cavallo, S. C. Gribar et al., "A critical role for TLR4 in the pathogenesis of necrotizing enterocolitis by modulating intestinal injury and repair," Journal of Immunology, vol. 179, no. 7, pp. 4808-4820, 2007.

[13] W. M. Richardson, C. P. Sodhi, A. Russo et al., "Nucleotidebinding oligomerization domain-2 inhibits toll-like receptor4 signaling in the intestinal epithelium," Gastroenterology, vol. 139, no. 3, pp. 904-e6, 2010.

[14] C. P. Sodhi, H. S. Shi, W. M. Richardson et al., "Toll-like receptor- 4 inhibits enterocyte proliferation via impaired $\beta$-catenin signaling in necrotizing enterocolitis," Gastroenterology, vol. 138, no. 1, pp. 185-196, 2010.

[15] W. Huang, Y. Tang, and L. Li, "HMGB1, a potent proinflammatory cytokine in sepsis," Cytokine, vol. 51, no. 2, pp. 119-126, 2010.

[16] C. P. Sodhi, M. D. Neal, R. Siggers et al., "Intestinal epithelial toll-like receptor 4 regulates goblet cell development and is required for necrotizing enterocolitis in mice," Gastroenterology, vol. 143, no. 3, pp. 708-718, 2012.

[17] N. Kettern, M. Dreiseidler, R. Tawo, and J. Höhfeld, "Chaperone-assisted degradation: multiple paths to destruction," Biological Chemistry, vol. 391, no. 5, pp. 481-489, 2010.

[18] A. Afrazi, C. P. Sodhi, M. Good et al., "Intracellular heat shock protein-70 negatively regulates TLR4 signaling in the newborn intestinal epithelium," The Journal of Immunology, vol. 188, no. 9, pp. 4543-4557, 2012.

[19] M. Good, R. H. Siggers, C. P. Sodhi et al., "Amniotic fluid inhibits Toll-like receptor 4 signaling in the fetal and neonatal intestinal epithelium," Proceedings of the National Academy of Sciences of the United States of America, vol. 109, no. 28, pp. 11330-11335, 2012.

[20] A. Soliman, K. S. Michelsen, H. Karahashi et al., "Platelet-activating factor induces TLR4 expression in intestinal epithelial cells: implication for the pathogenesis of necrotizing enterocolitis," PLoS ONE, vol. 5, no. 10, Article ID e15044, 2010.

[21] J. Lu, M. S. Caplan, D. Li, and T. Jilling, "Polyunsaturated fatty acids block platelet-activating factor-induced phosphatidylinositol 3 kinase/Akt-mediated apoptosis in intestinal epithelial cells," The American Journal of Physiology, vol. 294, no. 5, pp. G1181-G1190, 2008.

[22] N. J. Cherrington, T. E. Estrada, H. A. Frisk et al., "The hepatic bile acid transporters ntcp and Mrp2 are downregulated in experimental necrotizing enterocolitis," The American Journal of Physiology-Gastrointestinal and Liver Physiology, vol. 304, no. 1, pp. G48-G56, 2013.

[23] G. Terrin, A. Passariello, and R. B. Canani, "Drugs and tight junctions: adverse effects and opportunities for new therapeutic approaches," Journal of Pediatric Gastroenterology and Nutrition, vol. 54, no. 4, pp. 444-445, 2012.
[24] C. L. Leaphart, S. Dai, S. C. Gribar et al., "Interferon- $\gamma$ inhibits enterocyte migration by reversibly displacing connexin 43 from lipid rafts," The American Journal of Physiology, vol. 295, no. 3, pp. G559-G569, 2008.

[25] Y. S. Guner, A. Malhotra, H. R. Ford, J. E. Stein, and L. K. Kelly, "Association of Escherichia coli O157:H7 with necrotizing enterocolitis in a full-term infant," Pediatric Surgery International, vol. 25, no. 5, pp. 459-463, 2009.

[26] A. Passariello, G. Terrin, M. E. Baldassarre, M. de Curtis, R. Paludetto, and R. B. Canani, "Diarrhea in neonatal intensive care unit," World Journal of Gastroenterology, vol. 16, no. 21, pp. 2664-2668, 2010.

[27] C. E. Parra-Herran, L. Pelaez, J. E. Sola, A. K. Urbiztondo, and M. M. Rodriguez, "Intestinal candidiasis: an uncommon cause of necrotizing enterocolitis (NEC) in neonates," Fetal and Pediatric Pathology, vol. 29, no. 3, pp. 172-180, 2010.

[28] L. Leigh, B. J. Stoll, M. Rahman, and J. Jr. McGowan, "Pseudomonas aeruginosa infection in very low birth weight infants: a case-control study," The Pediatric Infectious Disease Journal, vol. 14, no. 5, pp. 367-371, 1995.

[29] R. H. Yolken and C. C. Franklin, "Gastrointestinal adenovirus: an important cause of morbidity in patients with necrotizing enterocolitis and gastrointestinal surgery," Pediatric Infectious Disease, vol. 4, no. 1, pp. 42-47, 1985.

[30] N. Gregersen, W. van Nierop, A. von Gottberg, A. Duse, V. Davies, and P. Cooper, "Klebsiella pneumoniae with extended spectrum beta-lactamase activity associated with a necrotizing enterocolitis outbreak," Pediatric Infectious Disease Journal, vol. 18, no. 11, pp. 963-967, 1999.

[31] G. Pelizzo, G. Nakib, I. Goruppi et al., "Isolated colon ischemia with norovirus infection in preterm babies: a case series," Journal of Medical Case Reports, vol. 7, no. 1, article 108, 2013.

[32] A. Bruyere, J. Bourgeois, P. Cochat, and M. Bethenod, "Neonatal ulcero-necrotizing enterocolitis and aspergillosis," Pediatrie, vol. 38, no. 3, pp. 185-189, 1983.

[33] C. J. Hunter and J. F. Bean, "Cronobacter: an emerging opportunistic pathogen associated with neonatal meningitis, sepsis and necrotizing enterocolitis," Journal of Perinatology, vol. 33, no. 8, pp. 581-585, 2013.

[34] S. Bagci, A. M. Eis-Hübinger, A. R. Franz et al., "Detection of astrovirus in premature infants with necrotizing enterocolitis," Pediatric Infectious Disease Journal, vol. 27, no. 4, pp. 347-350, 2008.

[35] K. P. Sawardekar, "Shigellosis caused by Shigella boydii in a preterm neonate, masquerading as necrotizing enterocolitis," Pediatric Infectious Disease Journal, vol. 24, no. 2, pp. 184-185, 2005.

[36] K. Kusuhara, M. Saito, Y. Sasaki et al., "An echovirus type 18 outbreak in a neonatal intensive care unit," European Journal of Pediatrics, vol. 167, no. 5, pp. 587-589, 2008.

[37] G. D. Overturf, M. P. Sherman, D. W. Scheifele, and L. C. Wong, "Neonatal necrotizing enterocolitis associated with delta toxin-producing methicillin-resistant Staphylococcus aureus," Pediatric Infectious Disease Journal, vol. 9, no. 2, pp. 88-91, 1990.

[38] J. Perez-Gonzalez, M. P. Ventura Faci, M. P. Samper Villagrasa, J. A. Gallego Beamonte, P. J. Ruiz Lazaro, and F. J. Castillo Garcia, "Epidemic outbreak of necrotizing enterocolitis caused by Clostridium difficile in full-term newborns," Anales Espanoles de Pediatria, vol. 44, no. 2, pp. 173-175, 1996. 
[39] F. E. Johnson, D. M. Crnic, M. A. Simmons, and J. R. Lilly, "Association of fatal Coxsackie B2 viral infection and necrotizing enterocolitis," Archives of Disease in Childhood, vol. 52, no. 10, pp. 802-804, 1977.

[40] A. F. Colver, S. J. Pedler, and P. M. Hawkey, "Severe campylobacter infection in children," Journal of Infection, vol. 11, no. 3, pp. 217-220, 1985.

[41] A. Lodha, N. de Silva, M. Petric, and A. M. Moore, "Human torovirus: a new virus associated with neonatal necrotizing enterocolitis," Acta Paediatrica, vol. 94, no. 8, pp. 1085-1088, 2005.

[42] J. Powell, M. A. Bureau, C. Pare, M. L. Gaildry, D. Cabana, and H. Patriquin, "Necrotizing enterocolitis. Epidemic following an outbreak of Enterobacter cloacae type 3305573 in a neonatal intensive care unit," The American Journal of Diseases of Children, vol. 134, no. 12, pp. 1152-1154, 1980.

[43] C. Chany, O. Moscovici, P. Lebon, and S. Rousset, "Association of coronavirus infection with neonatal necrotizing enterocolitis," Pediatrics, vol. 69, no. 2, pp. 209-214, 1982.

[44] H. Stein, J. Beck, A. Solomon, and A. Schmaman, "Gastroenteritis with necrotizing enterocolitis in premature babies," British Medical Journal, vol. 2, no. 5814, pp. 616-619, 1972.

[45] Y. Wang, J. D. Hoenig, K. J. Malin et al., "16S rRNA genebased analysis of fecal microbiota from preterm infants with and without necrotizing enterocolitis," The ISME Journal, vol. 3, no. 8, pp. 944-954, 2009.

[46] V. Mai, C. M. Young, M. Ukhanova et al., "Fecal microbiota in premature infants prior to necrotizing enterocolitis," PLOS ONE, vol. 6, no. 6, Article ID e20647, 2011.

[47] C. J. Stewart, E. C. L. Marrs, S. Magorrian et al., "The preterm gut microbiota: changes associated with necrotizing enterocolitis and infection," Acta Paediatrica, vol. 101, no. 11, pp. 1121-1127, 2012.

[48] B. Smith, S. Bodé, B. L. Petersen et al., "Community analysis of bacteria colonizing intestinal tissue of neonates with necrotizing enterocolitis," BMC Microbiology, vol. 11, article 73, 2011.

[49] J. Bhatia, "Human milk and the premature infant," Annals of Nutrition and Metabolism, vol. 62, no. 3, pp. 8-14, 2013.

[50] S. Sullivan, R. J. Schanler, J. H. Kim et al., "An exclusively human milk-based diet is associated with a lower rate of necrotizing enterocolitis than a diet of human milk and bovine milk-based products," Journal of Pediatrics, vol. 156, no. 4, pp. 562-267, 2010.

[51] M. Quigley and W. McGuire, "Formula versus donor breast milk for feeding preterm or low birth weight infants," Cochrane Database of Systematic Reviews, vol. 22, no. 4, Article ID CD002971, 2014.

[52] E. Polycarpou, S. Zachaki, M. Tsolia et al., "Enteral L-arginine supplementation for prevention of necrotizing enterocolitis in very low birth weight neonates: a double-blind randomized pilot study of efficacy and safety," Journal of Parenteral and Enteral Nutrition, vol. 37, no. 5, pp. 617-622, 2013.

[53] C. A. Nankervis, P. J. Giannone, and K. M. Reber, "The neonatal intestinal vasculature: contributing factors to necrotizing enterocolitis," Seminars in Perinatology, vol. 32, no. 2, pp. 83-91, 2008.

[54] A. van den Berg, R. M. van Elburg, E. Westerbeek, J. W. R. Twisk, and W. Fetter, "Glutamine-enriched enteral nutrition in very-low-birth-weight infants and effects on feeding tolerance and infectious morbidity: a randomized controlled trial," The
American Journal of Clinical Nutrition, vol. 81, no. 6, pp. 13971404, 2005.

[55] G. Terrin, A. Passariello, R. B. Canani, F. Manguso, R. Paludetto, and C. Cascioli, "Minimal enteral feeding reduces the risk of sepsis in feed-intolerant very low birth weight newborns," Acta Paediatrica, vol. 98, no. 1, pp. 31-35, 2009.

[56] R. Berni Canani, A. Passariello, V. Buccigrossi, G. Terrin, and A. Guarino, "The nutritional modulation of the evolving intestine.," Journal of clinical gastroenterology, vol. 42, supplement 3, pp. S197-S200, 2008.

[57] B. Dvorak, M. D. Halpern, H. Holubec et al., "Epidermal growth factor reduces the development of necrotizing enterocolitis in a neonatal rat model," The American Journal of PhysiologyGastrointestinal and Liver Physiology, vol. 282, no. 1, pp. G156G164, 2002.

[58] J. Feng, O. N. El-Assal, and G. E. Besner, "Heparin-binding epidermal growth factor-like growth factor reduces intestinal apoptosis in neonatal rats with necrotizing enterocolitis," Journal of Pediatric Surgery, vol. 41, no. 4, pp. 742-747, 2006.

[59] P. B. Sullivan, P. J. Lewindon, C. Cheng et al., "Intestinal mucosa remodeling by recombinant human epidermal growth factor(148 ) in neonates with severe necrotizing enterocolitis," Journal of Pediatric Surgery, vol. 42, pp. 462-469, 2007.

[60] R. B. Canani, M. Di Costanzo, L. Leone et al., "Epigenetic mechanisms elicited by nutrition in early life," Nutrition Research Reviews, vol. 24, no. 2, pp. 198-205, 2011.

[61] A. L. Bartholome, D. M. Albin, D. H. Baker, J. J. Holst, K. A. Tappenden, and T. Jaksic, "Supplementation of total parenteral nutrition with butyrate acutely increases structural aspects of intestinal adaptation after an $80 \%$ jejunoileal resection in neonatal piglets," Journal of Parenteral and Enteral Nutrition, vol. 28, no. 4, pp. 210-223, 2004.

[62] R. Terrin, R. Berni Canani, A. Passariello et al., "Zinc supplementation reduces morbidity and mortality in very-lowbirth-weight preterm neonates: a hospital-based randomized, placebo-controlled trial in an industrialized country," American Journal of Clinical Nutrition, vol. 98, no. 6, pp. 1468-1474, 2013.

[63] R. P. A. Wallin, A. Lundqvist, S. H. Moré, A. Von Bonin, R. Kiessling, and H. Ljunggren, "Heat-shock proteins as activators of the innate immune system," Trends in Immunology, vol. 23, no. 3, pp. 130-135, 2002.

[64] H. Bausinger, D. Lipsker, and U. Ziylan, "Endotoxin-free heatshock protein 70 fails to induce APC activation," European Journal of Immunology, vol. 32, no. 12, pp. 3708-3713, 2002.

[65] H. Lin, B. Su, A. Chen et al., "Oral probiotics reduce the incidence and severity of necrotizing enterocolitis in very low birth weight infants," Pediatrics, vol. 115, no. 1, pp. 1-4, 2005.

[66] S. A. Luedtke, J. T. Yang, and H. E. Wild, "Probiotics and necrotizing enterocolitis: finding the missing pieces of the probiotic puzzle," Journal of Pediatric Pharmacology and Therapeutics, vol. 17, no. 4, pp. 308-328, 2012.

[67] W. A. Mihatsch, C. P. Braegger, T. Decsi et al., "Critical systematic review of the level of evidence for routine use of probiotics for reduction of mortality and prevention of necrotizing enterocolitis and sepsis in preterm infants," Clinical Nutrition, vol. 31, no. 1, pp. 6-15, 2012.

[68] R. B. Canani and G. Terrin, "Gastric acidity inhibitors and the risk of intestinal infections," Current Opinion in Gastroenterology, vol. 26, no. 1, pp. 31-35, 2010. 
[69] G. Terrin, A. Passariello, M. De Curtis et al., "Ranitidine is associated with infections, necrotizing enterocolitis, and fatal outcome in newborns," Pediatrics, vol. 129, no. 1, pp. e40-e45, 2012.

[70] F. Bäckhed, C. M. Fraser, Y. Ringel et al., "Defining a healthy human gut microbiome: current concepts, future directions, and clinical applications," Cell Host and Microbe, vol. 12, no. 5, pp. 611-622, 2012.

[71] T. J. Borody, E. F. Warren, S. Leis, R. Surace, and O. Ashman, "Treatment of ulcerative colitis using fecal bacteriotherapy," Journal of Clinical Gastroenterology, vol. 37, no. 1, pp. 42-47, 2003.

[72] J. S. Bakken, "Fecal bacteriotherapy for recurrent Clostridium difficile infection," Anaerobe, vol. 15, no. 6, pp. 285-289, 2009. 


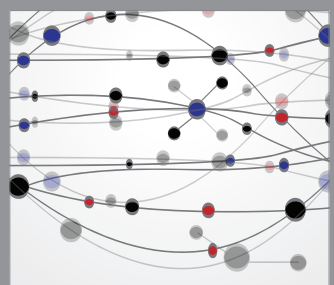

The Scientific World Journal
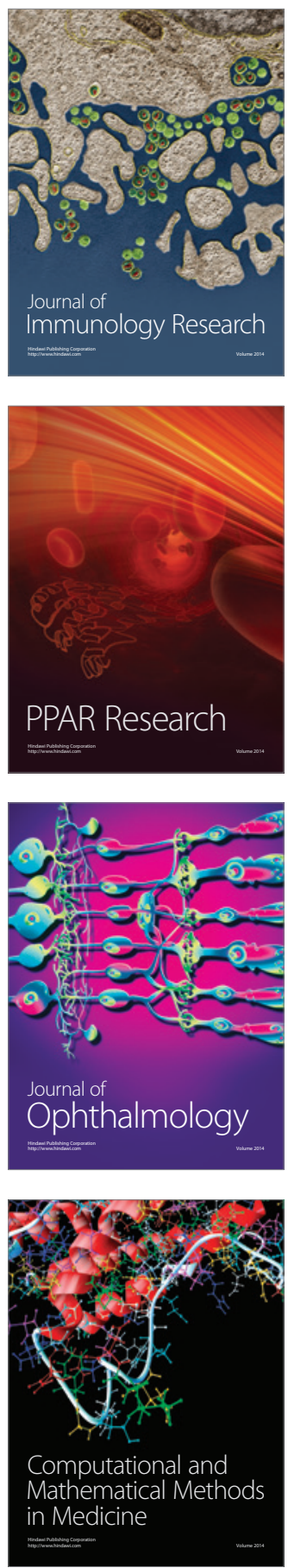

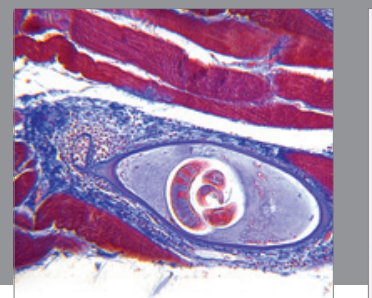

Gastroenterology

Research and Practice
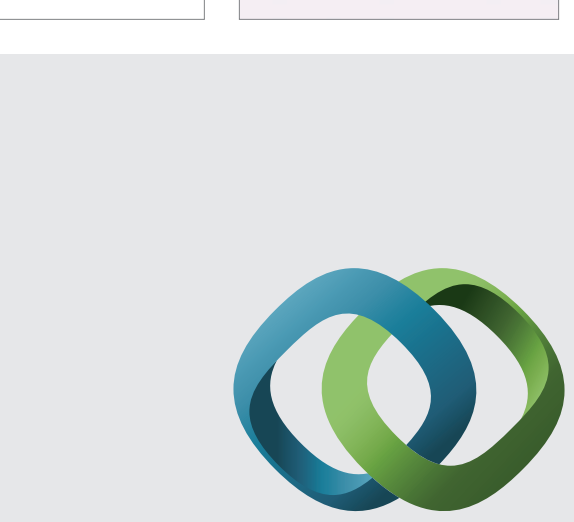

\section{Hindawi}

Submit your manuscripts at

http://www.hindawi.com
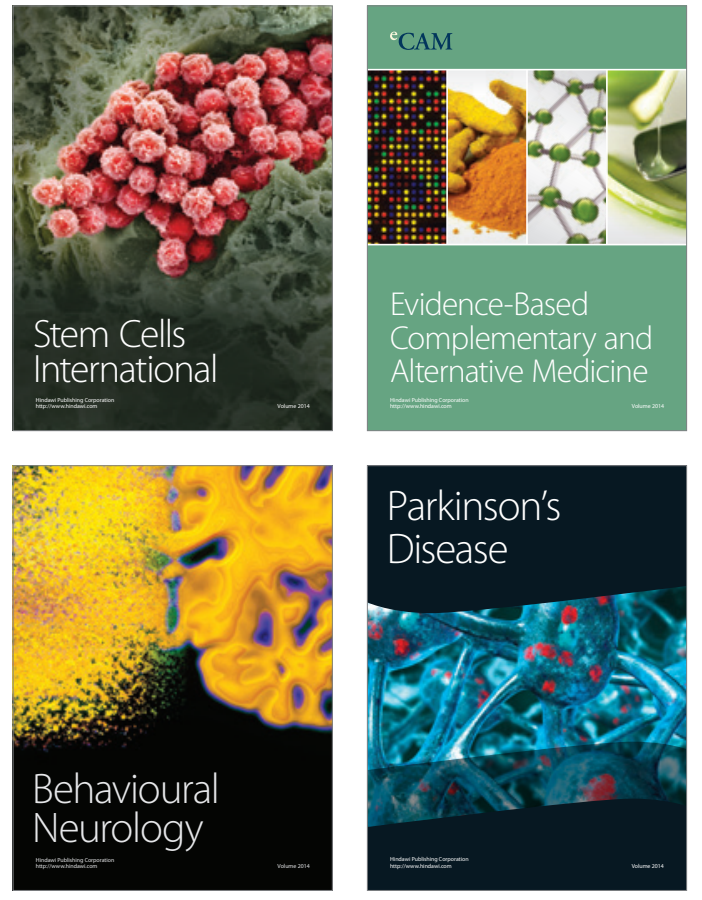
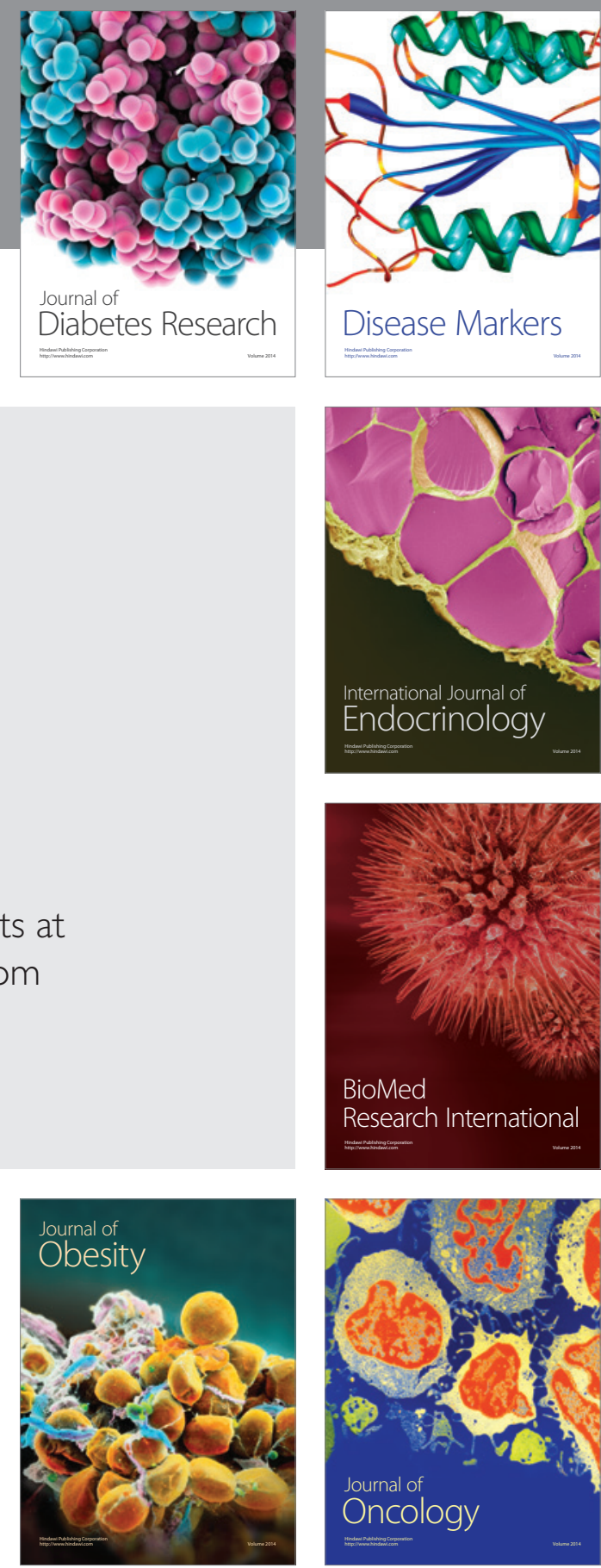

Disease Markers
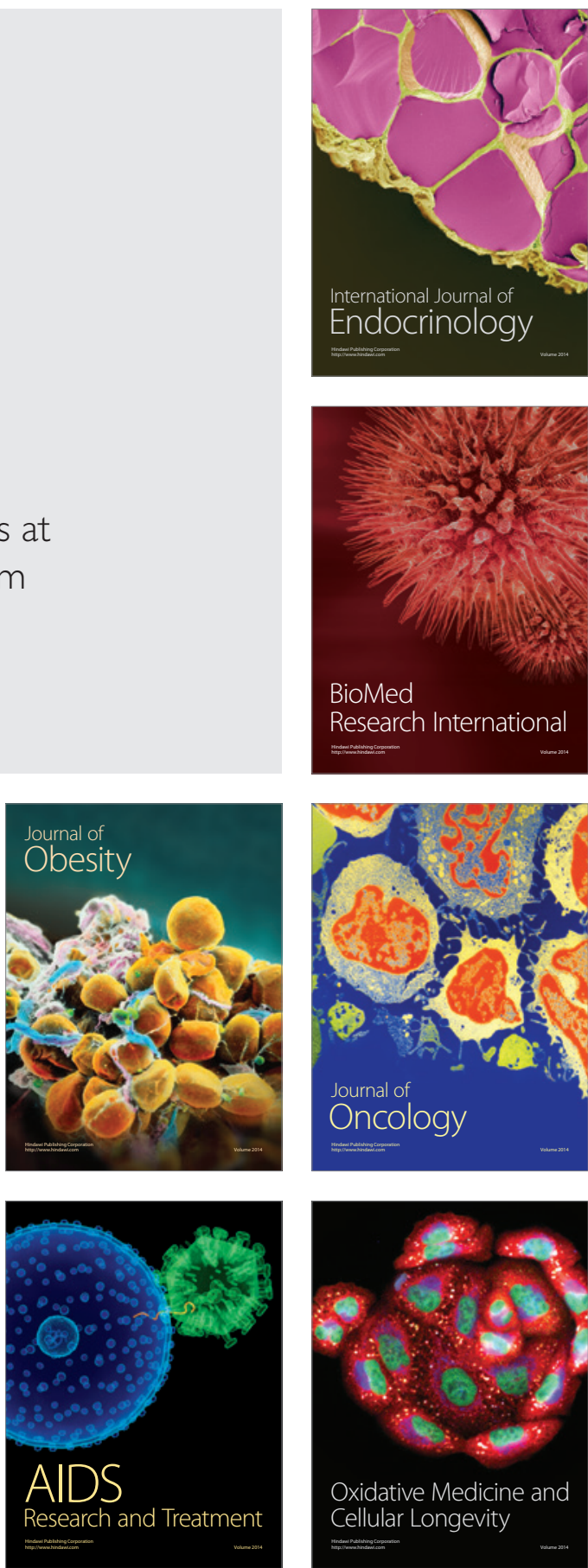